\title{
The Analysis of High School Students' Tendencies about Lifelong Learning
}

\author{
Ata Pesen*, Cevdet Epçaçan \\ Faculty of Education, Siirt University, Siirt, Turkey
}

Copyright $\bigcirc 2017$ by authors, all rights reserved. Authors agree that this article remains permanently open access under the terms of the Creative Commons Attribution License 4.0 International License

\begin{abstract}
This study was conducted to analyze whether there was a significant difference among secondary school students' tendencies about lifelong learning in terms of gender and grade variables. The participants were 466 students studying at different high schools in the central province of Siirt at $9^{\text {th }}, 10^{\text {th }}$ and $11^{\text {th }}$ grades, who were chosen randomly. 'Lifelong Learning Tendencies Scale' created by Coskun (2009) which has 27 items in it was used to gather related data. Frequency, mean and Mann-Whitney U test were used to evaluate the data. The results of the study showed that the participants' motivation and persistence levels were high in terms of lifelong learning tendency, however lack of interest and organization of learning subcomponents appeared to be at medium level according to student answers. Generally speaking, lifelong learning tendencies of high school students were at medium level. There was a statistically significant difference for the girls as for lifelong learning tendency but there was not such a difference among the students according to class grade variable.
\end{abstract}

Keywords Lifelong Learning, High School and Students

\section{Introduction}

Globalization, improvement in science and technology and increase in knowledge have caused immediate changes in the general knowledge and skills needed by modern world individuals (Akkoyunlu, 2002). The educational institutions generally tend to have an image of organization of learning rather than being a teaching entity as duration and quality of education have become of great importance for the motivation and required skills to be acquired by the students. For this reason, in such an age, compulsory education system needs to improve necessary skills for the students in order to enable them to learn how to learn and to prepare them for lifelong learning process (Demirel, 2010; Akt. Ozen, 2011).

Lifelong learning is a series of rules in terms of a group of organizational and procedural sequence for educational applications. The ultimate aim is lifelong learning - the learning which goes on a lifetime. "Learning" within this respect means literally learning not automatically within daily life. The concept of "lifelong", on the other hand, means an individual's intentional learning, which is life long and performed as necessary. Lifelong learning which is intentional has four main components: 1) It is intentional, that is, the students are aware of what they are doing and learning. 2) It has got concrete objectives and does not have generalizations or clichés like "to improve the mind". 3) For those reasons above, these objectives require the learners to have liability and responsibility for their own learning. 4) The learner plans to keep and save what s(he) has learnt for a considerable duration (Knapper\&Cropley, 2000). What caused the concept of "Lifelong learning" to come about was the necessity for individuals to learn the significant skills and knowledge at any time and age (Diker Coşkun \& Demirel, 2012; Sharples, 2000). Eventually, this caused the societies to evaluate and improve their members within the scope of lifelong learning (Soran, Akkoyunlu \& Kavak, 2006; Akkoyunlu, Kurbanoğlu, 2002). This condition which resembles to some kind of a chain reaction can be a result of necessities which are caused by other necessities. According to Demiralay and Karadeniz (2009), these necessities will create a need for such educational organizations to improve or enhance learning interests in individuals and to make them adopt the necessary components in terms of new changes or challenges they face during their learning process.

Learning goes on from "birth to death" and can be at any time or place regardless of age and atmosphere (MEB, 2014). That is, Lifelong learning consists of the first educational period taught by parents up to preschool education, from preschool period to all levels of primary and secondary education, from adulthood to old ages. For this reason, the ultimate distinction between young children, youngsters and adult education was abolished in lifelong learning which is mainly based on those various shareholders, young, adult, old to have necessary skills and knowledge according to their own needs. The main focus 
of lifelong learning includes the total of an individual's all learning process and the interest and effort in lifelong learning goes on a lifetime. (Bagc1, 2011)

There are a bulk of studies about lifelong learning tendencies in the literature most of which generally focus on adults only (Simmermon, 2009; Brahmi, 2007; Harwood, 2007; Loads, 2007; Chapman ve ark, 2003; Rausch, 2003; Code, 2001; Gustafson, 1992). The ones about lifelong learning in Turkey focus generally on teachers (Ayra\& Kösterelioğlu, 2015; Keskin\& Yazar, 2015; Yaman \& Yazar, 2015; Kilic \& Ayvaz Tuncel, 2014; Sahin \& Arcagök, 2014), teacher nominees (Guzel, 2017; Ergun \& Comert Ozata, 2016; Erdogan, 2014; Savuran, 2014; Oral \& Yazar, 2015; Kilic, 2014; Gencel Evin, 2013; Demirel \& Yagci, 2012; İzci \& Koc, 2012; Gurbuzturk \& Koc, 2002) and finally university students (Karakus, 2013; Diker Coskun \& Demirel, 2012; Diker Coskun, 2009) and only one study with general sampling (Haseski, Sahin, Yilmaz \& Erol, 2014). The only study on high school students about lifelong learning seems to be the one by Guzel, 2007. Therefore, this study may contribute to the literature in that its participants are all from secondary education levels.

\section{Aim of the Study}

This study aims at finding whether there is a statistically significant difference among high school students studying at different grades in terms of gender and class grade variables. The related research questions are as follows;

1. At which level are high school students about their lifelong learning tendencies?

2. Is there any statistically significant difference among students about their lifelong learning tendencies in terms of gender variable?

3. Is there any statistically significant difference among students about their lifelong learning tendencies in terms of grade variable?

\section{Methodology}

\section{Participants}

The participants in the study were 466 high school students who were selected randomly from 6 different high schools studying at $9^{\text {th }}, 10^{\text {th }}$ and $11^{\text {th }}$ grades in 2015-2016 educational years. The study was conducted in the second term of that educational year.

\section{Research Model}

Descriptive analysis model was used in the study. This model aims at describing the subject under the scope of the study without changing its present status. Descriptive studies depicts a condition as carefully and meticulous as possible (Buyukozturk vd., 2010)

\section{Data Collection}

As a data collection tool, "Lifelong Learning Tendencies Scale" created by Coskun (2009) was used. Likert type scale with 6 parameters consists of 4 subcomponents. The subcomponents of the scale are subsequently motivation (6 items), persistence (6 items), and lack of organization in learning (6 items) and lack of interest (9 items). Motivation and persistence are the positive ones and lack of interest in learning and lack of interest are negative ones in the scale. Therefore, in the course of the coding process of the collected data the negative items were inverse coded and analyzed afterwards. Total points, standard deviations and minimum, maximum or mean points were used to evaluate lifelong learning tendencies. The minimum point to be taken out of the scale is $(27 \times 1) 27$, average mean is $(27 \times 3,5)$ 94,5 , maximum point was $(27 \times 6) 162$. The minimum point for the first three components of the scale was $(6 \times 1) 6$, average mean was $(6 \times 3,5) 21$ and maximum point was (6x6) 36. The last component, lack of interest has got $(9 \times 1)$ 9 minimum points, $(9 \times 3,5) 31,5$ average and $(9 \times 6) 54$ maximum points (Coskun, 2009). From the points above, the general total point of the components of the scale namely, motivation, persistence, lack of organization in learning and lack of interest are high. This means that lifelong learning tendency is high. If the general point of the components is low, tendency level will be low. Cronbach Alpha reliability coefficient was 0,89 . In this study Cronbach Alpha reliability co efficient for the whole study was 0,87 , for motivation sub component, 0,71 , persistence- 0,71 , lack of organization in learning 0,81 and lack of interest was 0,88 .

\section{Data Analysis}

The data collected in the study was analyzed with SPSS 21,0 program. The significance level to be used in statistical analysis was $\mathrm{p} \leq 0,05$. Moreover $\mathrm{P}<0,01$ level was also used as a criteria. The first analysis of the data collected for the study resulted in a nonlinear distribution so frequency and standard deviation points were used for descriptive statistics. In addition, in order to see whether there is a statistically significant difference among the students about their lifelong learning tendencies in terms of "gender and grade" variable, Mann-Whitney U test was used.

\section{Findings}

The findings in this study were organized according to the subcomponents of the study and the data analyzed was shown accordingly in the tables.

The mean points and standard deviations of the answers of participants' answers to each item about lifelong learning tendency were shown in table 1 . 
Table 1. The mean points and standard deviations of the answers of participants'

\begin{tabular}{|c|c|c|c|}
\hline & Scale Items & $\overline{\mathrm{X}}$ & ss \\
\hline 1. & Learning new things all the time is a passion for me. & 5,47 & 1,00 \\
\hline 2. & I am more enthusiastic about learning new things and acquiring new skills than my classmates. & 5,09 & 1,09 \\
\hline 3. & If I believe that something will contribute to my self-improvement, I can acquire any knowledge easily. & 5,31 & 1,02 \\
\hline 4. & One of my ultimate goals of my lifetime is to self-improve by learning new things and acquire new skills constantly. & 5,20 & 1,10 \\
\hline 5. & $\begin{array}{l}\text { Even if I have got enough financial sources, I keep on learning new things and acquiring new skills for my } \\
\text { self-improvement. }\end{array}$ & 5,19 & 1,16 \\
\hline 6. & Learning new things and acquiring new skills in different areas for one's self improvement is just for me. & 5,16 & 1,17 \\
\hline 7. & I like spending most of my time researching for learning new things. & 4,59 & 1,33 \\
\hline 8. & I put great effort to learn something even if it can be very difficult and complicated at times. & 4,80 & 1,34 \\
\hline 9. & I put great effort immediately to learn new things and new skills regardless of whether it is compulsory or not. & 4,85 & 1,27 \\
\hline 10. & I try to create opportunities to learn new things and acquire new skills even if my schedule can be very busy. & 4,47 & 1,39 \\
\hline 11. & To learn new things and acquire new skills, I allocate extra budget from my personal spending. & 4,50 & 1,39 \\
\hline & $\begin{array}{l}\text { While I try to realize my objectives which are of top priority, I try to learn new things and acquire new skills even if } \\
\text { they are not related to my main objectives. }\end{array}$ & 4,66 & 1,42 \\
\hline 13. & My self-evaluation about what I have learnt generally hinders my learning new things. & 2,95 & 1,77 \\
\hline 14. & I do not care about what other people around me say about my learning process. & 3,60 & 1,88 \\
\hline 15. & I do not use any other source of data (book, internet etc.) about my occupation if it is not compulsory. & 3,66 & 1,89 \\
\hline 16. & I do not believe that I can learn new things and acquire new skills if they are not directly related to my profession. & 3,78 & 1,90 \\
\hline 17. & I think I will have difficulty in learning new things and acquiring new skills related to my profession. & 3,45 & 1,88 \\
\hline 18. & I would rather spend my time with my beloved ones than for my self-improvement. & 2,95 & 1,68 \\
\hline 19. & It seems unreasonable to me to learn new things and acquire new skills. & 3,63 & 1,87 \\
\hline & $\begin{array}{l}\text { It is not worth allocating any time or effort to learn new things or make up for my deficiencies if I am not responsible } \\
\text { for what I have learnt (ie. A compulsory exam) }\end{array}$ & 3,42 & 1,91 \\
\hline 21. & I would rather deal with my hobbies than try to put effort in learning new things except for compulsory issues & 3,04 & 1,81 \\
\hline & Feeling of learning new things and acquiring new skills constantly really disturbs me. & 3,57 & 1,87 \\
\hline 23. & I do not allocate any time to learn new things for just I wonder about them. & 3,74 & 1,95 \\
\hline 24. & I do not want to lose any time to do any research if it is not compulsory (exam, project etc.) & 3,48 & 1,92 \\
\hline 25. & I think that it is a waste of time attending to any course or seminar just to learn new things unless it is compulsory. & 3,57 & 1,94 \\
\hline & If it puts me to a financial crisis, I would not like to put any effort to learn new things and acquire new skills. & 3,49 & 1,92 \\
\hline & I think libraries are boring places. & 3,97 & 2,04 \\
\hline
\end{tabular}

The most striking item answered by students in the table is the third item in the scale namely "If I believe that something will contribute to my self-improvement, I can acquire any knowledge easily." The mean point for that item was very high. The second highest mean point belong to the item "One of my ultimate goals of my lifetime is to self-improve by learning new things and acquire new skills constantly." with a mean point of 5,12.

Table 2 below shows the related points of lifelong learning tendency, its subcomponents and standard deviations according to student answers.

Table 2. Points for lifelong learning tendency and standard deviations

\begin{tabular}{|c|c|c|c|c|}
\hline Lifelong learning tendency & $\mathrm{N}$ & $\overline{\mathrm{X}}$ & ss & $\begin{array}{c}\text { Participation } \\
\text { level }\end{array}$ \\
\hline Motivation & & 31,45 & 4,32 & 5,24 \\
\hline Persistence & & 27,89 & 5,38 & 4,65 \\
\hline Lack of organization in learning & 466 & 20,41 & 7,76 & 3,32 \\
\hline Lack of interest & & 31,95 & 12,52 & 3,55 \\
\hline The whole scale & & 111,71 & 21,50 & 4,13 \\
\hline
\end{tabular}

Table 2 above shows that for lifelong learning scale, for motivation subcomponent, $\bar{X}=31,45$, for persistence subcomponent $\bar{X}=27,89$, for lack of organization in learning subcomponent $\bar{X}=20,41$ and for lack of interest $\bar{X}$ $=32,01$. Generally the tendency level for the whole scale is $\bar{X}=111,78$. For this reason, lifelong learning tendency level is at medium level $(\overline{\mathrm{X}}=111,71)$, for motivation and persistence subcomponents the tendency level seems to be 
high in which $\overline{\mathrm{X}}=31,45$ and $\overline{\mathrm{X}}=27,89$ and lack of organization in learning and lack of interest subcomponents ( $\bar{X}=20,41, \bar{X}=32,95$ respectively) the tendency level is at medium level.

Mann-Whitney U-test was applied to evaluate the significance level of lifelong learning tendency according to gender level shown in table 3.

Table 3. The analysis of lifelong learning tendency level of secondary school students according to gender variable

\begin{tabular}{|c|c|c|c|c|c|c|}
\hline \multicolumn{2}{|l|}{ Variables } & \multirow{2}{*}{$\begin{array}{c}\mathbf{N} \\
142\end{array}$} & \multirow{2}{*}{\begin{tabular}{|c|} 
mean \\
194,32
\end{tabular}} & \multirow{2}{*}{$\begin{array}{c}\text { mean total } \\
27594,00\end{array}$} & \multirow{3}{*}{$\begin{array}{c}\mathbf{U} \\
17441,00\end{array}$} & \multirow{3}{*}{$\begin{array}{c}\mathbf{p} \\
, 000^{* *}\end{array}$} \\
\hline Motivation & Male & & & & & \\
\hline \multirow{5}{*}{ Lack of organization in learning } & Female & 324 & 250,67 & 81217,00 & & \\
\hline & Male & 142 & 187,21 & 26584,50 & \multirow{2}{*}{16431,50} & \multirow{2}{*}{, $000^{* *}$} \\
\hline & Female & 324 & 253,79 & 82226,50 & & \\
\hline & Male & 142 & 219,23 & 31130,00 & & \\
\hline & Female & 324 & 239,76 & 77681,00 & 20977,00 &, $012^{*}$ \\
\hline \multirow{2}{*}{ Lack of interest } & Male & 142 & 186,98 & 26551,50 & \multirow{2}{*}{16398,50} & \multirow{2}{*}{, $000 * *$} \\
\hline & Female & 324 & 253,89 & 82259,50 & & \\
\hline \multirow{2}{*}{ The whole scale } & Male & 142 & 182,58 & 25926,50 & \multirow{2}{*}{15773,00} & \multirow{2}{*}{, $000 * *$} \\
\hline & Female & 324 & 255,82 & 82884,50 & & \\
\hline
\end{tabular}

$* \mathrm{p} \leq 0,05, * * \mathrm{p} \leq 0,01$

When table 3 was analyzed, it can easily be seen that there is a statistically significant difference among students about their lifelong learning tendencies in terms of gender variable apart from lack of organization in learning subcomponent. According to the table, the girls outnumber the boys in terms of lifelong learning tendencies and its subcomponents. This might reveal that the girls are more enthusiastic about lifelong learning issues than the boys, they have more tendencies about motivation and persistence subcomponents than the boys on the other hand, and they seem to have more difficulties they face in terms of organization in learning and lack of interest subcomponents.

Kruskal-Wallis $U$ test was applied to see whether there is a statistically significant difference among students about their lifelong learning tendency according to class grade variable as shown in table 4.

Table 4. The analysis of lifelong learning tendencies of secondary school students in terms grade variable

\begin{tabular}{|c|c|c|c|c|c|c|}
\hline \multicolumn{2}{|l|}{ Variables } & $\mathbf{N}$ & Mean rank & sd & $\mathbf{x}^{2}$ & p \\
\hline \multirow{3}{*}{ Motivation } & 9. Grade & 217 & 226,32 & & & \\
\hline & 10. Grade & 125 & 233,33 & 2 & 1,74 & ,418 \\
\hline & 11. Grade & 124 & 246,23 & & & \\
\hline \multirow{3}{*}{ Persistence } & 9. Grade & 217 & 231,64 & & & \\
\hline & 10. Grade & 125 & 236,10 & 2 & 0,91 & ,955 \\
\hline & 11. Grade & 124 & 234,13 & & & \\
\hline \multirow{4}{*}{ Lack of organization in learning } & 9. Grade & 217 & 219,55 & & & \\
\hline & 10. Grade & 125 & 235,46 & 2 & 5,81 & ,055 \\
\hline & 11. Grade & 124 & 255,94 & & & \\
\hline & 9. Grade & 217 & 222,80 & & & \\
\hline \multirow[t]{3}{*}{ Lack of interest } & 10. Grade & 125 & 239,00 & 2 & 2,76 & 251 \\
\hline & 11. Grade & 124 & 246,68 & & & \\
\hline & 9. Grade & 217 & 222,75 & & & \\
\hline \multirow[t]{2}{*}{ The whole scale } & 10. Grade & 125 & 234,83 & 2 & 3,48 & ,175 \\
\hline & 11. Grade & 124 & 250,98 & & & \\
\hline
\end{tabular}

${ }^{*} \mathrm{p} \leq 0,05$

As shown in table 4, lifelong learning tendencies of students were compared according to the grade levels in terms of Kruskal-Wallis test. Lifelong learning tendency level of the participants seems to get higher in proportion to students' grade level increase but there was not a statistically significant difference according to the grade levels of them.

\section{Conclusions, Discussion and Suggestions}

The results of the study show that lifelong learning tendency level of students is at a medium level. They have a high level about motivation and persistence subcomponents on the other hand, for lack of interest and organization in learning components; they have got a medium level tendency. Guzel (2017) concluded in his/her study that lifelong learning tendency of high school students was at medium level. Meanwhile they have got a great deal of tendency of ignorance and motivation level was very low accordingly. When compared with the findings in this study, it might be said that lifelong learning tendency of the students was almost at the same level. However, for the subcomponents, some opposite levels appeared in the study. Such a difference is generally normal and acceptable in social sciences. Especially for regional differences where the scale was applied and 
various factors which affect lifelong learning tendencies of students might have played a role in such a difference.

Some of the studies in the literature about lifelong learning tendencies have similar results whereas some of the others have just the opposite. For example, Guzel (2017) and Kilic (2014) conducted studies on teacher nominees, Coskun \& Demirel (2012), Coskun (2009) on university students and concluded that lifelong learning tendencies of the participants were at a low level. On the other hand Ergun \& Ozata 2016, Oral \& Yazar (2015), Savuran (2014), Erdogan (2014), Karakus (2013), Gencel (2013), Izci \& Koc (2012) and Odemis (2013) found out in their studies that lifelong learning proficiencies, tendencies and perceptions of the participants were at a high level.

There was a statistically significant difference in all subcomponents and lifelong learning tendency levels of the students in terms of gender variable. Accordingly the girls have got more motivation and persistence levels than the boys in terms of lifelong learning tendency while in the lack of organization in learning and lack of interest subcomponents, they have got a less level than the boys. There are some other studies showing statistically significant differences as for the girls in the literature (Kiliç, 2014; Coskun \& Demirel, 2012; Izci \& Koc, 2012; Gencel, 2013; Coskun, 2009; Erdogan, 2014). Guzel (2017) conducted a study on high school students and found only statistically significant difference as for lack of motivation subcomponent. The author emphasized in the study that the boys were more ignorant and their lack of organization in learning was more than the girls while girls seemed to have more motivation and persistence subcomponent levels but these sublevels were not revealed as statistically significant. On the other hand, Yazar \& Keskin (2015) revealed in their studies that male teachers tended to have more lifelong learning tendency levels than the female teachers in terms of gender variable. Moreover, there are some studies showing the effect of gender differences on lifelong learning proficiencies (Guzel, 2017; Oral \& Yazar, 2015; Sahin \& Arcagok 2014; Sahin, Akbaslı \& Yelken, 2010).

When lifelong learning tendency levels were analyzed with its subcomponents according to grade levels of the students, lifelong learning tendency points seemed to get higher when the grade level increases from $9^{\text {th }}$ to $11^{\text {th }}$ grade however, there did not appear any statistically significant difference. Karakus (2013) conducted a study on college students and concluded that sophomores showed greater tendency levels than freshman students. Oral \& Yener (2015) revealed in their study that there was a statistically significant difference among teacher nominees in terms of lifelong learning perceptions according to grade variable. Meanwhile sophomores showed more tendency levels than the other grades. The findings of the study emphasized that sophomores had higher levels of perception than their counterparts about lifelong learning. Kilic \& Tuncel (2014), Ozciftci \& Bakir (2014) and Yaman \& Yazar (2015) concluded in their studies that teachers had a tendency to have a higher level of lifelong learning tendency up to a certain working experience, but after a specific working year, their tendency level started to decline.

The suggestions put forward according to the findings and results of the study are as follows;

1. There appears a need to conduct more qualitative studies for girls and boys, teachers and teacher nominees living in differing socio-economic and geographic classes.

2. More studies focusing on high school students' lifelong learning tendencies should be conducted to see the phenomenon from different angles.

\section{REFERENCES}

[1] Akkoyunlu, B. \& Kurbanoglu, S., (2002). Knowledge Literacy, TBD Informatics- Information culture Journal, Number: 83, s. 20-40.

[2] Ayra, M. \& Kosterelioglu, İ. (2015). The relationship between teachers' lifelong learning tendencies and professional self-efficacy perceptions. NWSA-Education Sciences, 10/1, 17-28.

[3] Bagci, E. (2011). Lifelong Learning policies in Turkey during the course EU membership. The University of Ondokuz Mayis, Faculty of Education journal, 30(2).

[4] Brahmi, A. F. (2007). Medical students' perceptions of lifelong learning at Indian a university School of medicine. Unpublished doctoral dissertation, Indiana University, USA.

[5] Buyukozturk, S., Cakmak Kilic, E., Akgun, Ö. E., Karadeniz, S \& Demirel F. (2010). Scientific Research Methods, Pegem Academy, Ankara.

[6] Chapman, J., Toomey, R., Gaff, J., McGlip, J., Walsh, M., Warren, E. \& Williams, I. (2003) Lifelong learning and teacher education. Canberra: Australian Government Department of Education, Science and Training. Available at:www.dest.gov.au/highered/eippubs.htm

[7] Code, L. (2001). Lifelong Learning in Master's Education. Unpublished MA thesis, Memorial University of Newfoundland, December, 2001.

[8] Demiralay, R. \& Karadeniz, S. (2008). Improvement in Knowledge literacy skills in primary school education for lifelong learning. Journal of Educational Sciences. 3/2, 89-119.

[9] Demirel, M. \& Yagci, E. (2012). Perceptions of primary school teacher nominees about lifelong learning, University of Hacettepe Journal, Private edition 1, 100-111.

[10] Diker Coskun, Y. \& Demirel, M. (2012). Lifelong learning tendencies of university students. University of Hacettepe, Faculty of Education Journal, 42, 108-120.

[11] Diker Coskun, Y. (2009). Evaluation of lifelong learning tendencies of university students in terms of several variables. Unpublished $\mathrm{PhD}$ thesis. University of Hacettepe, Institute of Social Sciences. 
[12] Erdogan, D. G. (2014). The factors affecting lifelong learning tendencies of teacher nominees. Unpublished $\mathrm{PhD}$ thesis, University of Abant İzzet Baysal, Bolu.

[13] Ergun, S. \& Comert Ozata S. (2016). Lifelong learning tendencies of students still attending to Preschool education department. International Journal of Human Sciences, 13/1, 1851-1861.

[14] Gencel Evin, I. (2013). Perceptions of teacher nominees' lifelong learning proficiency. Education and Science, $170 / 38,238-252$

[15] Gustafson, E. H. (1992). The Effectiveness of Teaching Lifelong Learning Skills to Students in A Community College Technical Program. PhD Thesis. Graduate Faculty of the School of Education United States International University, San Diego, 1992.

[16] Gurbuzturk, O. \& Koc, S. (2002), The evaluation of Information Literacy of teacher nominees in the $21^{\text {st }}$ century, E-Journal of New World Sciences Academy, 7/1, $27-48$.

[17] Guzel, H. (2017). Analysis of lifelong learning tendencies of teacher nominees. INNES The Journal of International Education Science, 10, 312-325.

[18] Harwood, A. (2007). Lifelong Learning: The Integration of Experiential Learning, Quality of Life Work in Communities, and Higher Education. PhD Thesis. The University of Montana, Spring 2007.

[19] Haseski, H. I., Şahin, Y. L., Yilmaz, E., \& Erol, O. (2014). The Investigation of the Relationship between Lifelong Learning Tendencies and Aims of Using Facebook/Facebook. Theories in education and application, 10(2), 331-351.

[20] Izci, E. \& Koc, S. (2012), The Evaluation of opinions of teacher nominees about lifelong learning process. University of Adryaman, Institute of Social Sciences Journal, 5/9, 101-112.

[21] Karakus, C. (2013), Lifelong learning Proficiency of Vocational College Students, Journal of Research in Education and Teaching, 2/3, 4

[22] Keskin, İ. \& Yazar, T. (2015). Examining digital competence of teachers within the context of lifelong learning based on of the twenty-first century skills. (Öğretmenlerin yirmi birinci yüzyıl becerileri ışığında ve yaşam boyu öğrenme bağlamında dijital yeterliliklerinin incelenmesi). Journal of Human Sciences, 12(2), 16911711.

[23] Kilic, Ç. (2014), Perceptions of teacher nominees about lifelong learning, Journal of Research in Education and Teaching, 3/4, 79-87.

[24] Kilic, H. \& Tuncel, Z. A. (2015). The level of individual self-improvement and lifelong learning tendency of primary school teachers. International Journal of Curriculum and Instructional Studies, 4(7).

[25] Knapper, C. \& Cropley, A. J. (2000). Lifelong learning in higher education. Psychology Press, p.11-12

[26] Koksal, N. \& Cogmen, S. (2013). Pre-service teachers as lifelong learners: University facilities for promoting their professional development. Eurasian Journal of Educational
Research, 53, 21-40.

[27] Loads, D. (2007, June). Effective learning advisers' perceptions of their role in supporting lifelong learning. Teaching in Higher Education, Retrieved June 17, 2017, from

http://content.ebscohost.com/pdf19 22/pdf/2007/THD/01 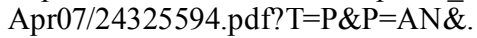

[28] MEB, (2014). Lifelong Learning strategy and Action Plan of Turkey.

http://hbogm.meb.gov.tr//meb_iys_dosyalar/2015_04/2002 5555_hbostratejibelgesi_2014_2018.pdf.

[29] Oral, B. \& Yazar, T., (2015), Evaluation of lifelong learning perceptions of teacher nominees according to various variables, Electronic Institute of Social Sciences Journal, 14/52, 1-11.

[30] Ozciftci, M. \& Cakir, R. (2015). Evaluation of lifelong learning tendencies and competence in educational technology standards of teachers, Educational Technology Theory and Application, 5(1).

[31] Ozen, Y. (2011). Perceptual learning theory, learning by changing and improving for a lifetime. University of Dicle. Journal of Institute of Social sciences, 3(6), 1-16.

[32] Rausch, A.S. (2003). A case study of lifelong learning in Japan: objectives, curriculum, L accountability, and visibility. International Journal of Lifelong Education. 22/5, 518-532.

[33] Savuran, Y. (2014). Lifelong learning skills of English teacher nominees compared to their mentors, Unpublished MA thesis, University of Hacettepe, Ankara.

[34] Sharples, M. (2000). The design of personal mobile technologies for lifelong learning. Computers \& Education, 34(3), 177-193.

[35] Simmermon, W.J. (2009). A study of a two year college and how it fosters lifelong learning and empowerment. Unpublished doctoral dissertation, University of South Dakota, USA.

[36] Simpson, J.A. (1972). Today and tomorrow in European adult education. A study of the present.

[37] Soran, H., Akkoyunlu, B., \& Kavak, Y. (2006). Lifelong learning skills and training of trainers program: a sample of Hacettepe University, University of Hacettepe, Faculty of education journal, 30(30).

[38] Sahin, C. \& Arcagok, S. (2014). Evaluation of lifelong learning competence of teachers in terms of various variables. Journal of Social Sciences/Sosyal Bilimler Dergisi, 7(16).

[39] Sahin, M. Akbasli, S. \& Yelken Yanpar, T (2010) .Key Competences for lifelong learning; The case of prospective teachers. Educational Research and Review, 5/10, 545-556.

[40] Yaman, F. \& Yazar, T. (2015). Evaluation of Lifelong learning tendencies of teachers. Example of province of Diyarbakir. Kastamonu Educational Journal, 23/4, 1553-1566.

[41] Yazar, T. \& Keskin, I. (2015). Evaluation of digital competence of teacher nominees in terms of lifelong learning. International Journal of Human Sciences, 12/2, 1691-1711. 